University of Louisville ThinkIR: The University of Louisville's Institutional Repository

Faculty Scholarship

2017

\title{
Intersecting disadvantages: race, gender, and age discrimination among attorneys.
}

Todd Collins

Tao L. Dumas

Laura Moyer

University of Louisville, laura.moyer@louisville.edu

Follow this and additional works at: https://ir.library.louisville.edu/faculty

Part of the American Politics Commons, and the Law Commons

\section{Original Publication Information}

This is the peer reviewed version of the following article:

Collins, Todd A., Tao L. Dumas, and Laura P. Moyer. "Intersecting Disadvantages: Race, Gender, and Age Discrimination Among Attorneys." 2017. Social Science Quarterly 98(5): 1642-1658.

which has been published in final form at http://doi.org/10.1111/ssqu.12376

This article may be used for non-commercial purposes in accordance with Wiley Terms and Conditions for Use of Self-Archived

Versions.

\section{ThinkIR Citation}

Collins, Todd; Dumas, Tao L.; and Moyer, Laura, "Intersecting disadvantages: race, gender, and age discrimination among attorneys."

(2017). Faculty Scholarship. 397.

https://ir.library.louisville.edu/faculty/397 
Intersecting Disadvantages: Race, Gender, and Age Discrimination among Attorneys

\author{
Todd A. Collins \\ Western Carolina University \\ tcollins@email.wcu.edu \\ Tao L. Dumas \\ The College of New Jersey \\ dumast@tcnj.edu \\ Laura P. Moyer* \\ University of Louisville \\ laura.moyer@louisville.edu
}

\begin{abstract}
*Authors' names are listed alphabetically, and each contributed equally to the project. We thank the Public Policy Institute at Western Carolina University for providing support. We also are appreciative of helpful feedback received on earlier versions of the paper from Michelle Deardorff, Allison Harris, attendees of the 2015 APSA meeting, and participants in the University of Kentucky research forum. Appendices and replication files are available at http://louisville.edu/politicalscience/political-science-faculty/laura-p.-moyer-ph.d. Direct all correspondence to Laura Moyer, 205 Ford Hall, Department of Political Science, University of Louisville, Louisville, KY 40292.
\end{abstract}




\section{Intersecting Disadvantages: Race, Gender, and Age Discrimination among Attorneys}

Objective. This article explores the impact of race, gender, age, and intersectionality on attorneys' perceptions of unfair treatment by other lawyers and on satisfaction with their legal careers. Method. Using an original survey of over 2,000 attorneys, ordered logit is utilized to analyze attorneys' perceptions of disparate treatment based on race, gender, and age and to test whether minority female attorneys face unique barriers within their professional relationships. Results. We find that minority women are more likely than others to perceive unfair treatment based on race, gender, and age. This also contributes to lower career satisfaction for attorneys who are women of color than for other groups. Conclusion. The findings have important implications for understanding attorney relationships and potential barriers for minority groups within a profession's culture. These obstacles not only impact attorneys, but could also influence attorney choice for citizens and the prospects for a representative judiciary. 


\section{Intersecting Disadvantages: Race, Gender, and Age Discrimination among Attorneys}

"A black woman partner from a major Chicago firm noted that she had been taken for a court reporter at every deposition she had ever attended" (Rhode 1994: 65).

The composition of the legal profession has seen dramatic changes in the last fifty years, transitioning from an exclusively white-male institution to one that is substantially more diverse in its inclusion of women and people of color. Yet a broad array of research points to a variety of indicators that suggest minorities and women are not fully incorporated into all facets of the profession. For example, women and minorities have greater attrition from the legal profession (Sander 2006; Hull and Nelson 2000) and face significant disadvantages in advancement (Gorman and Kay 2014; Stake, Dau-Schmidt, and Mukhopahaya 2007). Furthermore, as the opening quote illustrates, attorneys who are "outsiders" in terms of their race and gender may face bias and skepticism from other members of the legal system when they try to participate on equal terms with white men. In this paper, we explore the extent to which the intersecting characteristics of age, race, and gender affect attorneys' perceptions of unequal treatment by other attorneys, and how such perceptions, if they exist, influence subsequent assessments of career satisfaction.

Although understudied, attorneys are critical decision-makers in the judicial process, especially at the pretrial stage, where the bulk of all disputes are resolved (Eisenberg and Lanvers 2009; Galanter 2004; Miller and Sarat 1980), and where attorneys possess far greater control over a case's resolution than judges or the parties themselves. And while it is well established that attorney expertise (McAtee and McGuire 2007; McGuire 1995) and quality (Szmer et. al. 2014; Haynie and Sill 2007; Haire et al. 1999) are strong predictors of lawyers' success in court, we know much less about the impact of attorney demographics on the building blocks of negotiations: interactions with other attorneys. Indeed, the bulk of the existing literature examines the race and gender of judges or litigants rather than attorneys (Haire and Moyer 2015; Boyd, Epstein, and Martin 2010; Kastellec 2013; Collins and Moyer 2008), or focuses on attorney gender in the courtroom (Szmer et al. 2010; Szmer et al. 2013). To our knowledge, there is no existing systematic study that takes an "intersectional" approach to understanding how attorneys experience discrimination by their professional peers.

To fill this gap in the literature, we analyze original survey data from over 2,000 practicing attorneys to investigate whether women of color are more likely than other race-gender cohorts to perceive that they are treated unfairly by other attorneys, and what impact such perceptions may have on their satisfaction with their careers. We begin by outlining the research on bias and stereotypes and then specifically examine the treatment and experiences 
of women and minorities in the legal profession. From this discussion, we predict that minority female attorneys, as members of two traditionally "outsider" groups, will have experiences distinctive from those of minority males or white females. Our findings show that female minority attorneys face unique challenges in the professional setting, as they alone perceive unfair treatment based on three characteristics: race, gender, and age. They also report lower levels of career satisfaction than other race-gender cohorts. Beyond the personal experiences faced by the attorneys themselves, our findings have implications for both the administration of justice and the pipeline to judicial positions, particularly if race and gender affects the ability of attorneys to build and maintain successful professional relationships. They also contribute to our scholarly understanding of how the intersection of demographic traits shapes individual experiences and perceptions.

\section{Bias and Stereotyping in the Legal Profession}

Before identifying explanations for bias against female and minority attorneys, it is instructive to note several key institutional characteristics of the legal profession that likely structure how disadvantage operates. First, it is well established that "repeat players" in the legal system (Galanter 1974) have a distinct set of advantages that outsiders and novices lack (Dumas, Haynie, and Daboval 2015; Colvin 2011; Galanter 2004). A major component of the repeat-player advantage is the development of working relationships with other attorneys, which build the trust needed for successful negotiations (Johnson and Waldfogel 2002; Gilson and Mnookin 1994). Past successful interactions between actors allow for the development of a mutual reputation for honesty and a commitment to continued trust between the actors (Molm, Takahaski, and Peterson 2000). Relatedly, attorneys' positions within professional networks also affect their ability to be influential in their interactions with opposing counsel, as well as to advance their own professional standing (Rhode 2011). Lastly, attorneys frequently operate in small, task-oriented group settings, with other legal personnel from their law firm and attorneys from other firms. As mentioned earlier, these small group negotiations are crucial because the overwhelming majority of civil and criminal cases are resolved without a trial. Thus, clients benefit when they are represented by counsel who have developed a rapport with opposing attorneys, which can promote a mutually beneficial and more expedient resolution to a dispute. Conversely, attorneys who lack this rapport and mutual trust may find it more challenging to secure a favorable outcome for their clients.

Given this institutional setting, the literature points to several mechanisms that can serve to disadvantage attorneys who are not white males. One major paradigm for understanding bias against women and minorities 
views this as an example of bias against outsiders. Brewer (1999) finds that individuals express more trust toward members of their own groups, compared to individuals outside their groups. In particular, high-status groups tend to exhibit more bias toward non-members than individuals in low-status groups (Brewer and Brown 1998). Within the legal profession, white males are the majority demographic group and also the group that dominates the rank of partner (NALP 2010). As Rhode (2011: 1053) writes, "Loyalty, cooperation, favorable evaluations, mentoring, and the allocation of rewards and opportunities all increase in likelihood for individuals who are similar in important respects, including sex, race, and ethnicity. The result is to prevent outsiders from developing 'cultural capital': access to advice, support, desirable assignments, and client development activities."

Along these lines, network analyses show that white males occupy different employment networks than women and minorities, and these networks are not equal in prestige or their ability to translate into successful employment outcomes (Dinovitzer 2011; Kim 2009). Because trust helps to smooth the way for social exchanges, traits like race and gender can stand in for trustworthiness in the absence of information (McDonald 2011: 320), which can impact the effectiveness of an attorney not from the majority demographic group. The literature on attorney attrition and advancement suggests that women and minority attorneys frequently report exclusionary practices within their firms that isolate non-traditional attorneys from key opportunities and networks (Kay and Hagan 2003; Gorman and Kay 2014: 49).

Other research from social psychology finds that persistent stereotypes about the performance abilities of different groups can affect decision making by small groups. Stereotypes about individuals can become selffulfilling prophecies, benefiting individuals with traits associated with high performance expectations and undermining individuals with traits associated with low expectations (Correll and Ridgeway 2006). One federal taskforce concluded, "women attorneys face credibility problems not found by their male counterparts. This is a cause for concern, because credibility is directly related to one's ability to influence others" (Nelson 1993-4: 733).

Relatedly, scholarship suggests that the public views women and minority lawyers as less competent and proficient than white male attorneys (Brown and Campbell 1997) and that clients are less deferential to women lawyers (Bogoch 1997). Because of widely held associations between masculine-associated traits and law, female attorneys are disadvantaged when people perceive "feminine" behavior as deviating from the stereotypical lawyer role (Pierce 1995; Rhode 2002). As to racial stereotypes, "blacks and Latinos bump up against assumptions that they are less intelligent, less industrious, and generally less qualified; even if they graduated from an elite law 
school, they are assumed to be beneficiaries of affirmative action rather than meritocratic selection. Asian Americans are saddled with the myths of the 'model minority'; they are thought to be smart and hardworking, but not sufficiently assertive to command the confidence of clients and legal teams" (Rhode 2011: 1050). Black attorneys also report being mistaken for criminal defendants or other court personnel (Rhode 1994, 2011) and hearing racial slurs and jokes from other attorneys and judges (Hays and Stevens 1991: B1).

While overt discrimination has undoubtedly lessened compared to earlier eras (Moyer and Haire 2015), the evidence indicates that bias against outsider groups has continued to prevail, to a lesser extent, in the legal profession and in the courtroom. ${ }^{1}$ However, the extensive body of work cataloguing discriminatory treatment faced by women and minorities in the legal profession has generally viewed these as discrete and not overlapping phenomena. ${ }^{2}$ We argue that this may not accurately reflect the complex experiences of individuals from "out groups" within the profession. In the following section, we outline how intersecting identities should affect attorneys' perceptions of unfair treatment by their professional peers.

\section{The intersection of race, gender, and other characteristics}

A considerably smaller body of work has specifically focused on the challenges facing minority women attorneys. Women of color face discrimination not just as a function of their gender or their race, but in ways particular to their "intersectional" status as minority women (Crenshaw 1989; Collins and Moyer 2008). For instance, a study of EEOC employment discrimination claims found that black women filed more claims than any other group of women, and that while a significant share of their claims were for sex discrimination, the largest share of their claims were for race discrimination (Ortiz and Roscigno 2009). In contrast, nearly all of the claims

filed by white women were for sex discrimination. Consistent with the argument that anti-discrimination law tends to conceive of discrimination as being based on either race or sex (Crenshaw 1989), analyses of EEO legal cases find that minority women are more likely to lose than white women, nonwhite men, and white men (Best et al. 2011).

In comparisons with other race-gender cohorts, female minority lawyers are paid less than minority men, white woman, and white men; they also report having limited access to client development possibilities at nearly twice the rate of minority men (Epner 2006). One study of Chicana attorneys highlighted the women's frustrations with underestimation of their abilities in their jobs and the constant need to "prove" themselves (Garcia-Lopez 
2008). Moreover, the subjects reported being frequently mistaken for non-lawyer staff, such as court reporters or interpreters, when they appeared in court or arrived at other law firms for depositions (Garcia-Lopez 2008: 601-3, 609). Similarly, a 2006 study of minority women attorneys concluded, "[B]eing a woman and a member of a racial minority group made it more difficult to become integrated into [a] law firm, created career hurdles that white men did not experience, and proved to be emotionally draining” (Epner 2006: 11).

Finally, researchers across a number of fields have documented how stereotypes about age can intersect with gender and other characteristics to pose unique disadvantages. The particular effect of age, however, varies by context, and little systematic research has examined lawyers in particular. In an experiment of voting preferences, Sigelman and Sigelman (1982) find that ageism was actually a stronger force than either sexism or racism in candidate selection, with older individuals from all race and gender groups being at a disadvantage. In the employment setting, there appears to be a curvilinear relationship between age and perceptions of discrimination, with women in their 20s and women in their 50s reporting the highest levels (Gee, Pavalko, and Long 2007). Young women in white-collar jobs report that their employers treat them as lacking in credibility: "You are not necessarily taken seriously, because you are a young woman. Sometimes it is just because you are young, sometimes it is because you are not a man, and sometimes it is both" (Jyrkinen and McKie 2012: 68). An ABA focus group quoted one female lawyer's frustrations on this point: "I get so many comments because I'm Asian, I'm a woman, and I look young. They try the first-year associate thing, they try the honey thing, they ask where are you from, you speak English so well, you don't even have an accent. ... When I first started practicing it would make me incensed to the point where I would lose my concentration and focus" (Epner 2006: 10). These comments suggest that, because it can be difficult to pinpoint the precise reason for unfair treatment, individuals will necessarily differ in how they label discrimination (e.g., sexism, racism, ageism, or some combination of the three). Women's age is also perceived to affect their ability negatively at younger ages than it is for men. Duncan and Loretto (2004) studied workers at a financial firm and found that women in the 30 to 40 age range were discriminated against both for being too old and too young, while men in their 30s reported negative treatment due only to their youth. Thus, to gain a holistic assessment of perceptions of bias, researchers need to broaden the scope of inquiry beyond a "single-axis" framework, considering how various traits influence individuals' perceptions about how they are treated by their professional peers. 


\section{Implications of bias and discrimination}

Taken as a whole, the literature suggests that attorneys who are not white males will be very likely to report unfair treatment by other attorneys. Following existing research, we anticipate that women will report more unfair treatment based on sex, and nonwhite attorneys will report more unfair treatment based on race. However, we also expect that perceptions of unfairness will manifest themselves in less obvious ways. For instance, a white woman might perceive that she was treated disrespectfully because of her age, whereas a black woman in the same situation might interpret the unfair treatment as racism. In both cases, however, the individual's treatment is a function of their "other-ness" or outsider status. Because of this, researchers must be careful not to construct their indicators too narrowly, as doing so likely underestimates perceptions of discrimination.

To avoid this problem, our hypotheses focus on ways that unfair treatment is likely to be experienced by white women and minority women, taking a broad view. This leads us to the following two predictions:

H1: White women will be more likely than white men to perceive unfair treatment based on age.

H2: Women of color will be more likely than white women, white men, or minority men to perceive unfair treatment on the basis of age, race, and gender.

But do negative experiences and perceptions of unfair treatment hurt non-traditional attorneys' assessments of their careers in the law? The available evidence is mixed. Overall, among all attorneys, career satisfaction is fairly high (Organ 2011), and most work finds little to no gender or racial differences on questions about career satisfaction (Organ 2011; Dinovitzer and Garth 2007; Stake, Dau-Schmidt, and Mukhopadhaya 2007). However, a meta-analysis of career satisfaction surveys found that one consistent trend was that more recent entrants into the profession report less satisfaction than more seasoned attorneys (Organ 2011; Stake, Dau-Schmidt, and Mukhopadhaya 2007).

Given the mixed findings from prior studies on career satisfaction for female and minority attorneys, we may not expect race or gender alone to influence career satisfaction. However, because female minority attorneys are at the intersection of two out-groups, we would expect that they face unique obstacles that may tarnish their views of the legal profession and diminish their career satisfaction. This suggests the following hypothesis:

H3: Minority female attorneys will report lower levels of career satisfaction than white males, white females, or minority males. 


\section{Research Design}

To assess perceptions of unfair treatment and career satisfaction, we conducted an online survey of every licensed attorney from North Carolina. Following a common approach in the literature, we administered the survey via email using Qualtrics software. While relatively new, Internet-based survey techniques have been shown to perform as accurately as more traditional surveying methods, such as mail and phone surveys (Berrens et al. 2003). Over a period of one month, we received 2,774 usable responses from 24,775 attorneys. By opening the survey to all attorneys, we avoid the potential problem of selecting an unrepresentative pool of respondents through sampling. However, self-selection bias may still be a concern as attorneys that opt in to the survey could have different views than those that did not take the survey. As has often been noted, response representativeness is most important for survey accuracy, compared to focusing solely on the response rate (Cook, Health, and Thompson 2000: 821). In comparing demographic characteristics of our sample to both national and state estimates, our sample closely mirrors national estimates based on major demographic factors and practice types (American Bar Association 2015; North Carolina State Bar 2013). ${ }^{3}$ While it is possible that selection bias may occur based on the method of reaching the respondents (Couper, Kapteyn, Schonlau, and Winter 2007), these concerns are lessened because of the close match between our sample demographics and out-of-sample estimates.

In the survey, respondents were asked several questions about aspects of their occupation, such as the type of practice (private, government, in-house counsel, legal aid, etc.), size of firm (if in private practice), and issue areas that characterize their practice (such as bankruptcy, family law, criminal defense, or 27 other legal categories). Other individual demographic factors were also asked, including race, gender, years of practice, and law school, among others (see the Appendix for the survey instrument).

Table 1 provides information about the measurement and distribution of all variables. Of most interest to this study, the survey asked questions about career satisfaction and perceptions of unfair treatment by other attorneys. Specifically, we asked respondents if they felt they had ever been treated unfairly in negotiations with

another attorney because of their race, their gender, or their age. Respondents could select from one of four ordered choices: "no"; "yes, but rarely"; “yes, occasionally"; or "yes, often.” We also asked respondents to answer how satisfied they were with their careers as attorneys and provided a seven-point Likert-type scale for responses. As displayed in Table 1, these serve as our dependent variables in the models.

[Table 1 about here] 
Our main independent variables include the respondent's race and gender and the intersectionality of these important characteristics. As discussed above, we believe that female attorneys will be more likely to perceive unfair treatment in their interactions with other attorneys due to gender stereotypes. Similarly, attorneys of color may perceive that they are being treated differently due to racial biases. Our models also allow us to determine whether minority females hold different opinions than their minority male or white female colleagues, as they are at the intersection of two "out groups." Further, our models allow us to determine if demographic characteristics also influence perceptions of unfair treatment based on age.

In addition to race and gender, we note that several other factors could influence perceptions of unfair treatment and career satisfaction. Career longevity may be a related factor (Dau-Schmidt and Mukhopadhaya 1999). For example, one cohort analysis revealed that attorneys with 15 years of practice were more satisfied with their careers overall than attorneys just five years out of law school (Stake, Dau-Schmidt, Mukhopadhay 2007). We include a variable for the years since passing the bar as a control for experience. ${ }^{4}$

Prior studies have also noted that the type of practice in which an attorney works can influence satisfaction rates. One such study found that attorneys at larger firms were more satisfied with their careers than those working at small and medium sized firms (Stake, Dau-Schmidt, and Mukhopadhaya 2007). This influence could stem from the fact that larger firms pay higher salaries, as higher pay is correlated with higher career satisfaction (Gorman 2005; Hagan 1990; Heinz, Nelson, and Laumann 2001). We include a series of indicator variables (0 or 1$)$ variables for five different practice types that generally follow the ABA's categorization (see Table 1 for full listing). We use "medium or large firm" as the excluded category.

Other scholars have highlighted the impact of law school prestige on attorneys' career prospects (Dinovitzer 2011). Kay and Hagan (2003: 498-9) conclude that "[t]he contacts that elite law school students make through their schooling play a significant role in shaping their career path." To account for the influence that law school experiences may play on later professional experiences and career satisfaction, we follow the approach of prior studies by including categories based on the US News and World Report's law school rankings (Dinovitzer and Garth 2007; Dinovitzer 2011; Sander and Bambauer 2012). These are broken down into six categories which track the law school rankings, with our excluded category being those considered "fourth tier" (ranked above 150). 


\section{Results}

As an initial exploration of perceptions of disparate treatment, we first examined the percentage of respondents who indicated they had been subjected to unfair treatment either "occasionally" or "often." (See the appendix for full results.) As expected, minority attorneys perceived unfair treatment based on race more often than white attorneys ( $24 \%$ of minority respondents, compared to $0.6 \%$ of white respondents). Likewise, female attorneys also were more likely than men to perceive unfair treatment than males due to their gender $(37 \%$ compared to $0.8 \%)$. Women also report experiencing more disparate treatment based on age than men (29\% compared to $11 \%$ ), consistent with the literature. Applying intersectionality groupings, however, allows for a more nuanced examination of the responses. Viewed this way, female minority attorneys report higher levels of unfair treatment than any other group based on all three categories (gender, race, and age). Thirty percent of female minority attorneys report unfair treatment based on race "occasionally" or "often," while less than a fourth (23\%) of minority males reported disparate treatment based on race with the same frequency. Minority women were also more likely to report unfair treatment based on age than other respondents; they were also more likely to report unfair treatment based on gender (42\%) than white women (36\%).

Given these differences, we next examine respondents' perceptions of unfair treatment in a multivariate analysis. Because our unfair treatment variables include four ranked categories, but not an interval-level scale, we use an ordered logit modeling strategy (Liao 1994). We include variables for race-gender cohorts (with white males as the excluded term), five practice settings (with medium/large firms as the reference category), whether the respondent practices in a rural or urban area, years of practice, career satisfaction, and law school prestige (with schools ranked above 151 by US News and World Report being the excluded category). ${ }^{5}$ Descriptive statistics for these variables are reported in Table 1.

[Table 2 about here]

The first model in Table 2 examines perceptions of unfair treatment based on race. As expected, nonwhite men and nonwhite women perceive higher levels of unfair treatment than white men, controlling for experience, practice type, rural or urban practice setting, and law school prestige. However, there are no significant differences between minority women and minority men on this question. Few trends emerge in our practice-type variables, with the exception that government attorneys appear to experience more unfair treatment based on race than those at larger private law firms. This may be a function of the concentration of minority attorneys employed in 
government jobs; previous research documents how the government has been historically more amenable to hiring non-traditional attorneys than private practice (Haire and Moyer 2015). We also see that those with higher overall career satisfaction are less likely to report unfair treatment based on race. Next, the second column in Table 2 displays the results for unfairness based on gender. In support of our expectations, both groups of women (white and minority) are more likely to report unfair treatment when compared to white men. When we rotate the excluded category, we see that minority women are more likely to perceive unfairness than minority men, but are not statistically different from white women as a group. Again, there are few differences based on practice characteristics or law school prestige, but career satisfaction is linked to perceptions of unfair treatment.

The last column in Table 2 displays the results for perceptions of unfair treatment based on age. Recall that our descriptive analysis showed that minority women as a group had the highest percentage of respondents who perceived they were subjected to occasional or frequent unfair treatment based on their age. After controlling for other factors, Table 2 shows that both nonwhite and white females perceive statistically significantly higher levels of age bias than white males. ${ }^{6}$ Career satisfaction continues to play an important role, as it did in the previous three models. For each type of unfair treatment, the more satisfied respondents were with their legal careers, the less likely they were to report more frequent unfair treatment.

\section{[Figure 1 about here]}

To examine these findings in more depth, Figure 1 presents the predicted probability of reporting that unfair treatment occurs either occasionally or often, graphed against years of practice. The top left panel shows the likelihood of reporting unfair treatment either occasionally or often, based on age, for each race-gender group. Here, we see a consistent decline in the likelihood of unfair treatment based on age across all groups as experience increases. Clearly, less experienced attorneys of both genders and all races perceive more unfair treatment early on in their careers, but white men (represented by the long, dashed line) report this the least often. To illustrate, a white male attorney with five years of experience has a probability of .26 of reporting at least occasional unfair treatment based on age. In comparison, a similarly situated white woman would have a .49 probability, and a minority woman would have a .40 probability of reporting such treatment.

Next, the bottom left panel shows that minority women are slightly more likely to report unfair treatment based on gender than are white women. Attorneys with more experience report unfair treatment less frequently, perhaps indicating that less satisfied individuals exit the legal profession, leaving behind those who are more 
satisfied with their career choice. Alternatively, this may indicate the existence of generational differences in perceiving gender bias among different cohorts of women, or that more recent entrants into the profession are more sensitive to perceiving bias. However, because we lack panel data, we are unable to evaluate whether an individual's perceptions change over time.

Finally, the graph in the top right corner displays the probability of at least occasional unfair treatment based on race for minority women and minority men. At most periods in an attorney's career, women of color are about twice as likely as minority men to report unfair treatment based on race. For example, a minority woman with five years experience has a likelihood of .29 of reporting at least occasional unfair treatment based on race, while a similarly situated minority man with the same amount of experience has a .14 probability.

As discussed above, prior studies paint a mixed picture about the relationship between attorney race and gender and career satisfaction. To examine how perceptions of unfair treatment might influence career satisfaction, we estimate two models where the dependent variable is a seven-point scale. (Higher values represent greater levels of career satisfaction.) Table 3 presents the results of these models, which show some support for our argument that minority women are uniquely disadvantaged. In the first model, nonwhite women report significantly lower levels of career satisfaction than all other race-gender cohorts, after controlling for other factors. ${ }^{7}$ This differs from the previous models, where minority women were not distinguishable from minority men (on race and age bias) or white women (on gender and age bias). Attorneys who had practiced for longer periods of time reported more career satisfaction, while solo practitioners, attorneys in small firms, and those in our residual practice category expressed lower levels of career satisfaction compared to those in larger firms. We see no discernable differences due to law school prestige.

[Table 3 about here]

However, it is possible that career satisfaction may be related to both an individual's identity (e.g., being a black woman) and perceptions of unfair treatment. Not every minority and/or female lawyer has experienced unfair treatment, but these individuals may express lower satisfaction with their careers for other reasons not captured in our model. ${ }^{8}$ To examine this possibility, we estimate an additional model predicting career satisfaction. In column 2 (Table 3), the model includes both the race-gender cohort variables and perceptions of unfair treatment based on race, gender, or age. While there are not significant differences in career satisfaction between women of color and white males after controlling for perceptions of unfairness, we do see that perceptions of age unfairness 
again exert significant influence. Although diagnostics indicate that multicollinearity does not impact our results, the results for the age unfairness variable may be tapping into experiences that are disproportionately perceived by minority women, compared to other groups, and thus closely tied to satisfaction. ${ }^{9}$ To put it another way, because our data show that, particularly among newer attorneys, white men perceive age discrimination less often than other groups, then our findings for age and career satisfaction suggest that "outsider" groups feel they are subject to more criticism and scrutiny because of their inexperience - and this, in turn, lowers their career satisfaction.

\section{Discussion}

While it may be unsurprising that women will perceive more gender bias and racial minorities will perceive more racial bias by professional peers, our findings about minority women's perceptions tell an important story that is often overlooked in the literature. Specifically, minority female attorneys, being part of two outgroups, occupy a distinctive place in a profession traditionally dominated by white males. Our results show that women of color are the only group who reports higher levels of unfair treatment based on race, gender, and age. Moreover, we find some evidence that nonwhite females are more likely than other race-gender cohorts to report lower levels of satisfaction with their legal career. Age discrimination also emerges as an issue of concern for under-represented groups, who are more likely to report frequently experiencing unfair treatment on this basis than white men. Indeed, the biggest gaps between white men and other race-gender cohorts appear at the early career stage, which may be a contributing factor to the higher levels of attrition seen for minority and female lawyers. At a minimum, this suggests that relative inexperience, as a marker of difference, does not equally impact all groups.

Like all research, this study has its limitations. Because the sample consists of attorneys licensed in one state, the ability to generalize to other parts of the country may be limited. We do note that over $10 \%$ of our respondents stated that their primary place of practice was outside of North Carolina, that about $30 \%$ of our respondents practiced primarily in federal courts (an area of practice that is similar from state to state), and that our sample's demographic attributes closely mirrored estimates of attorneys across the country. Again, while there is no a priori reason to expect that attorneys in our sample are different from attorneys nationwide, it is possible that future studies in other areas of the country may find different results.

We also recognize that our study examines perceptions of unfair treatment but does not explore documented instances of unfair treatment. Nevertheless, we believe that perceptions are worthy of further study. For example, we find evidence that these perceptions of unfair treatment have an effect on career satisfaction, 
which may influence whether an attorney remains in the profession. If certain groups, like women of color, express less satisfaction with their legal careers, this could significantly limit the pool of diverse judicial candidates by increasing the likelihood that they will drop out of the profession. Going forward, it will be important to ascertain whether perceptions of unfairness change over the course of an individual's career, which is something that we cannot address with our research design. Future research is needed to investigate how perceptions about professional relationships impact attorneys' career longevity, effectiveness, and advancement, all of which have implications for diversifying the legal profession.

In addition to researching an understudied set of actors in our legal system, this project also highlights the importance of assessing a wide range of potential influences on individual behaviors and perceptions. Following other work on intersectionality, our findings denote the importance of looking at the effects of overlapping characteristics, such as age, wealth, gender, race, or other salient attributes. In this way, our research stretches outside the courtroom and past the courthouse halls. Regardless of the institutional setting, examining the intersection of multiple traits and characteristics is an important step in refining our understanding of human behavior. 


\section{References}

American Bar Association. 2015. Lawyer Demographics. American Bar Association: Chicago, IL. Available at http://www.americanbar.org/content/dam/aba/administrative/market_research/lawyer-demographicstables-2014.authcheckdam.pdf

Berrens, Robert P., et al. 2003. "The Advent of Internet Surveys for Political Research: A Comparison of Telephone and Internet Samples." Political Analysis 11: 1-22.

Best, Rachel Kahn, et al. 2011. "Multiple Disadvantages: An Empirical Test of Insectionality Theory in EEO Litigation.” Law \& Society Review 45 (4): 991-1025.

Bogoch, Bryna. 1997. “Gendered Lawyering: Difference and Dominance in Lawyer-Client Interaction.” Law and Society Review 31 (4): 677-712.

Boyd, Christina L., Lee Epstein, and Andrew D. Martin. 2010. "Untangling the Causal Effect of Sex on Judging." American Journal of Political Science 54 (2): 389-411.

Brewer, Marilyn. 1999. “The psychology of prejudice: ingroup love or outgroup hate?” Journal of Social Issues 55(3): 429-444.

Brewer, Marilynn B., and Rupert J. Brown. 1998. "Intergroup Relations.” In The Handbook of Social Psychology, Vol. 2, $4^{\text {th }}$ ed. DT Gilbert et al, eds. Boston: McGraw-Hill.

Brown, Robert L., and Shelia Campbell. 1997 "How the Public Views Female and Black Attorneys.” Arkansas Law Review 33: 22-28.

Carson, Clara. 2004. “The Lawyers Statistical Report: The U.S. Legal Profession in 2000.” Chicago: American Bar Foundation.

Chambliss, Elizabeth. 2000. Miles to Go 2000: Progress of Minorities the Legal Profession. Chicago: American Bar Association, Commission on Racial and Ethnic Diversity in the Profession.

Cohen, David L., and John L. Peterson. 1981. "Bias in the Courtroom: Race and Sex Effects of Attorneys and Juror Verdicts.” Social Behavior and Personality 9 (1): 81-87.

Collins, Todd A. and Laura Moyer. 2008. “Gender, Race, and Intersectionality on the Federal Appellate Bench.” Political Research Quarterly 61: 219-227.

Cook, Colleen, Fred Heath, and Russel L. Thompson. 2000. “A Meta-Analysis of Response Rates in Web- or Internet-Based Surveys.” Educational and Psychological Measurement 60: 821-836. 
Colvin, Alexander J. S. 2011. “An Empirical Study of Employment Arbitration: Case Outcomes and Processes.” Journal of Empirical Legal Studies 8(1): 1-23.

Correll, Shelley J., and Cecilia L. Ridgeway. 2006. "Expectation States Theory.” Handbook of Social Psychology. Ed., John Delamater. New York: Klewater Academic.

Couper, Mick, P., Arie Kapteyn, Matthias Schonlau, and Joachim Winter. 2007. "Noncoverage and nonresponse in an Internet Survey.” Social Science Research 36: 131-148.

Crenshaw, Kimberle. 1989. "Demarginalizing the Intersection of Race and Sex: A Black Feminist Critique of Antidiscrimination Doctrine, Feminist Theory, and Antiracist Doctrine, Feminist Theory, and Antiracist Politics." University of Chicago Legal Forum 140: 139-67

Dau-Schmidt, Kenneth G., and Kaushik Mukhopadhaya. 1999. "The Fruits of Our Labors: An Empirical Study of the Distribution of Income and Job Satisfaction Across the Legal Profession.” Journal of Legal Education 49(3): 342-66.

Dinovitzer, Ronit. 2011. “The Financial Rewards of Elite Status in the Legal Profession.” Law \& Social Inquiry 36 (4): 971-98.

Dinovitzer, Ronit, and Bryant G. Garth. 2007. "Lawyer Satisfaction in the Process of Structuring Legal Careers." Law \& Society Review 41 (1): 1-50.

Dinovitzer, Ronit, Nancy Reichman, and Joyce Sterling. 2009. “The Differential Valuation of Women’s Work.” Social Forces 88(2): 819-64.

Dixon, Jo, and Carroll Seron. 1995. "Stratification in the Legal Profession: Sex, Sector, and Salary." Law and Society Review 29(3): 381-412.

Dumas, Tao L., Stacia L. Haynie, and Dorothy Daboval. 2015. “Does Size Matter? The Influence of Law Firm Size on the Probability of Litigant Success.” Justice System Journal 36 (4): 341-54.

Duncan, C. and Loretto, W. 2004. "Never the right age? Gender and age-based discrimination in employment." Gender, Work and Organization 11(1): 95-115.

Eisenberg, Theodore and Charlotte Lanvers. 2009. "What is the Settlement Rate and Why Should We Car?" Journal of Empirical Legal Studies 6 (1): 111-46. 
Epner, Janet E. 2006. "Visible Invisibility: Women of Color in Law Firms.” American Bar Association Commission on Women in the Profession. Available at: http://www.americanbar.org/content/dam/aba/marketing/women/visibleinvisibility.authcheckdam.pdf

Fox, John, and Georges Monette. 1992. "Generalized Collinearity Diagnostics.” Journal of the American Statistical Association. 87: 178-183.

Fuchs Epstein, Cynthia, Robert Saute, Bonnie Oglensky, and Martha Gever. 1995. "Glass Ceilings and Open Doors: Women's Advancement in the Legal Profession.” Fordham Law Review 64 (2): 306-449.

Garcia-Lopez, Gladys. 2008. "Nunca Te Toman En Cuenta (They Never Take You Into Account).” Gender and Society 22 (5): 590-612.

Galanter, Marc. 1974. "Why the "Haves" Come Out Ahead: Speculations on the Limits of Legal Change." Law and Society Review 9: 95-160.

Galanter, Marc. 2004. "The Vanishing Trial: An Examination of Trial and Related Matters in Federal and State Courts.” Journal of Empirical Legal Studies 1(3): 459-570.

Gee, Gilbert C., Eliza K. Pavalko, and J. Scott Long. 2007. “Age, Cohort, and Perceived Age Discrimination: Using the Life Course to Assess Self-Reported Age Discrimination.” Social Forces 86(1): 265-290.

Gilson, Ronald J. and Robert H. Mnookin. 1994. "Disputing Through Agents: Cooperation and Conflict between Lawyers in Litigation." The Columbia Law Review 94: 509-66.

Gorman, Elizabeth H. 2005. "Gender Stereotypes, Same-Gender Preferences, and Organizational Variation in the Hiring of Women: Evidence from Law Firms.” American Sociological Review 70: 702-28.

Gorman, Elizabeth H., and Fiona M. Kay. 2014. "Law Firm Employment Practices and the Representation of Minority Associates and Partners.” LSAC Grants Report Series. Available at: $\underline{\text { http://www.lsac.org/lsacresources/research/all/gr/gr-14-01 }}$

Hagan, John. 1990. “The Gender Stratification of Income Inequality among Lawyers. Social Forces 68(3): 835-55. Law \& Social Inquiry 28 (2): 483-519.

Haire, Susan Brodie, Stefanie A. Lindquist, and Roger Hartley. 1999. “Attorney Expertise, Litigant Success, and Judicial Decision-Making in the U.S. Courts of Appeals." Law \& Society Review 33: 667-85.

Haire, Susan B. and Laura P. Moyer. 2015. Diversity Matters: Judicial Policy Making in the U.S. Courts of Appeals. Charlottesville, VA: University of Virginia Press. 
Hahn, Peter W., and Susan D. Clayton. 1996. "The Effects of Attorney Presentation Style, Attorney Gender, on Juror Decisions." Law and Human Behavior 20(5): 533-54.

Hays, Arthur S., and Amy Stevens. 1991. "Racism is Said to Pervade New York Courts," Wall Street Journal, June 5 , at B6.

Haynie, Stacia L., and Kaitlyn L. Sill. 2007. "Experienced Advocates and Litigation Outcomes: Repeat Players in the South African Supreme Court of Appeal." Political Research Quarterly 60: 443-453.

Heinz, John P., Robert L. Nelson, and Edward O. Laumann. 2001. "The Scale of Justice: Observations on the Transformation of Urban Law Practice.” Annual Review of Sociology 27: 337-62.

Hodgson, Stuart, and Burt Pryor. 1984. "Sex Discrimination in the Courtroom: Attorney’s Gender and Credibility." Psychological Reports 55(2): 483-86.

Hull, Kathleen E., and Robert L. Nelson. 2000. “Assimilation, Choice, or Constraint? Testing Theories of Gender Difference in the Careers of Lawyers." Social Forces 79(1): 229-264.

Johnston, Jason Scott, and Joel Waldfogel. 2002. “Does Repeat Play Elicit Cooperation? Evidence from Federal Civil Litigation.” Journal of Legal Studies 31: 1-30.

Jyrkinen, Marjut, and Linda McKie. 2012. “Gender, Age, and Ageism: Experiences of Women Managers in Finland and Scotland." Work, Employment, and Society 26(1): 61-77.

Kaheny, Erin, John J. Szmer, and Tammy A. Sarver. 2011. "Women Lawyers Before the Supreme Court of Canada." Canadian Journal of Political Science 44(1): 83-109.

Kastellec, Jonathan. 2013. "Racial Diversity and Judicial Influence on Appellate Courts.” American Journal of Political Science 57 (1): 167-183.

Kay, Fiona M., and John Hagan. 2003. "Building Trust: Social Capital, Distributive Justice, and Loyalty to the Firm.” Law \& Social Inquiry 28 (2): 483-519.

Kim, Harris H. 2009. "Networks, Information Transfer, and Status Conferral: The Role of Social Capitol in Income Stratification among Lawyers.” The Sociological Quarterly 50 (1): 61-87.

Liao, Tim Funting. 1994. Interpreting Probability Models-Logit, Probit, and Other Generalized Linear Models. Sage Publications: Thousand Oaks, CA.

McAtee, Andrea, and McGuire, Kevin T. 2007. " Lawyers, Justices, and Issue Salience: When and How Do Legal Arguments Affect the U.S. Supreme Court?" Law and Society Review 41: 259-278. 
McDonald, Steve. 2011. "What's in the 'old boys' network? Accessing the social capital in gendered and racialized networks." Social Networks 33: 317-330.

McGuire, Kevin T. 1995. "Repeat Players in the Supreme Court: The Role of Experienced Lawyers in Litigation Success." Journal of Politics 57: 187-196.

Miller, Richard E., and Austin Sarat. 1980-81. "Grievances, Claims, and Disputes: Assessing the Adversary Culture." Law and Society Review 15: 525-566.

Molm, Linda, D., Nobuyuki Takahashi, and Gretchen Peterson. 2000. "Risk and Trust in Social Exchange: An Experimental Test of a Classical Proposition.” American Journal of Sociology 105: 1396-1427.

Moyer, Laura P., and Susan B. Haire. 2015. "Trailblazers and Those That Followed: Personal Experiences, Gender, and Judicial Empathy." Law \& Society Review 49(3): 665-689.

Nelson, Dorothy, W. 1993-4. "Introduction to the effects of gender in the federal courts: the final report of the Ninth Circuit Gender Bias Task Force.” Southern California Law Review 67: 731 - 738.

North Carolina State Bar. 2013. Demographic Survey Report, available at http://www.ncbar.gov/gxweb/wp_demographicsreport.aspx, last accessed on March 13, 2015.

Organ, Jerome M. 2011. "What do We Know about the Satisfaction/Dissatisfaction of Lawyers? A Meta-Analysis of Research on Lawyer Satisfaction and Well-Being.” University of St. Thomas Law Journal 8 (2): 22574.

Ortiz, Susan Y., and Vincent J. Roscigno. 2009. "Discrimination, Women and Work: Processes and Variations by Race and Class.” The Sociological Quarterly 50: 336-59.

Pierce, Jennifer L. 1995. Gender Trials: Emotional Lives in Contemporary Law Firms. Berkeley: University of California Press.

Rhode, Deborah L. 1994. Professional Responsibility: Ethics by the Pervasive Method. Boston: Little \& Brown. --- 2002. “What Needs Fixing? Gender and the Profession.” Hofstra Law Review 30: 1001-13. --- 2011. “From Platitudes to Priorities: Diversity and Gender Equity in Law Firms.” Georgetown Journal of Legal Ethics 24: 1041- 1077.

Sander, Rachel H. 2006. "The Racial Paradox of the Corporate Law Firm.” North Carolina Law Review 84: 17561822. 
Sander, Richard, and Jane Bambauer. 2012. “The Secret of My Success: How Status, Eliteness, and School Performance Shape Legal Careers.” Journal of Empirical Legal Studies 9 (4): 893-930.

Scherer, Nancy, and Brett Curry. 2010. “Does Descriptive Race Representation Enhance Institutional Legitimacy? The Case of the U.S. Court.” Journal of Politics 72: 90-104.

Sigal, Janet J., Braden-Maguire, M. Hayden, and N. Mosley. 1985. "The Effect of Presentation Style and Sex on Lawyer o Jury Decision-Making Behavior.” Psychology: A Quarterly Journal of Human Behavior 22 (3/4): 13-19.

Sigelman, Lee, and Carol K. Sigelman. 1982. "Sexism, Racism, and Ageism in Voting Behavior: An Experimental Analysis." Social Psychology Quarterly 45(4): 263-269.

Stake, Jeffery Evans, Kenneth G. Dau-Schmidt, and Kaushik Mukhopadhaya. 2007. "Income and Career Satisfaction in the Legal Profession: Survey Data from Indiana Law School Graduates.” Journal of Empirical Legal Studies 4 (4): 939-81.

Sumoski, Diane M. 2001. "Bridging the Gender Gap.” Litigation 27 (3): 31-35.

Szmer, John and Martha Humphries Ginn. 2014. "Examining the Effects of Information, Attorney Capability, and Amicus Participation on the Supreme Court." American Politics Research 42 (3): 441-71.

Szmer, John, Erin B. Kaheny, Tammy Sarver, and Mason DeCamillis. 2013. "The Impact of Attorney Gender on Decision Making in the United States Courts of Appeals.” Journal of Women, Politics \& Policy 34 (1): 72-100.

Szmer, John J., Tammy A. Saver, and Erin B. Kaheny. 2010. "Have We Come a Long Way Baby? The Influence of Attorney Gender on Supreme Court Decision Making." Politics \& Gender 6: 1-36.

Wilkins, David B. 1999. "Partners without power? A Preliminary Look at Black Partners in Corporate Law Firms." Journal of the Institute for the Study of Legal Ethics 2: 15-48. 
Table 1: Coding of Variables

\begin{tabular}{|c|c|c|}
\hline Variable & Coding & Descriptive Statistics \\
\hline $\begin{array}{l}\text { Unfair Treatment } \\
\text { Based on Race }\end{array}$ & $\begin{array}{l}1=\text { no } \\
2=\text { yes, rarely } \\
3=\text { yes, occasionally } \\
4=\text { yes, often }\end{array}$ & $\begin{array}{l}92.3 \%(2063) \\
4.8 \%(107) \\
2.6 \%(57) \\
0.4 \%(9)\end{array}$ \\
\hline $\begin{array}{l}\text { Unfair Treatment } \\
\text { Based on Gender }\end{array}$ & $\begin{array}{l}1=\text { no } \\
2=\text { yes, rarely } \\
3=\text { yes, occasionally } \\
4=\text { yes, often }\end{array}$ & $\begin{array}{l}72.4 \%(1631) \\
14.5 \%(327) \\
10.9 \%(245) \\
2.2 \%(50) \\
\end{array}$ \\
\hline $\begin{array}{l}\text { Unfair Treatment } \\
\text { Based on Age }\end{array}$ & $\begin{array}{l}1=\text { no } \\
2=\text { yes, rarely } \\
3=\text { yes, occasionally } \\
4=\text { yes, often }\end{array}$ & $\begin{array}{l}62.0 \%(1395) \\
21.0 \%(472) \\
13.7 \%(308) \\
3.3 \%(74) \\
\end{array}$ \\
\hline $\begin{array}{l}\text { Overall Career } \\
\text { Satisfaction }\end{array}$ & $\begin{array}{l}\text { Slider: higher values represent more satisfaction } \\
1 \\
2 \\
3 \\
4 \\
5 \\
6 \\
7\end{array}$ & $\begin{array}{l}4.03 \%(88) \\
8.61 \%(188) \\
2.75 \%(60) \\
7.15 \%(156) \\
19.1 \%(417) \\
35.2 \%(768) \\
23.2 \%(506)\end{array}$ \\
\hline $\begin{array}{l}\text { Race/Gender } \\
\text { Intersectionality }\end{array}$ & $\begin{array}{l}\text { White men } \\
\text { White women } \\
\text { Nonwhite men } \\
\text { Nonwhite women }\end{array}$ & $\begin{array}{l}62.4 \%(1407) \\
28.8 \%(648) \\
3.7 \%(83) \\
5.1 \%(116)\end{array}$ \\
\hline Years in Practice & Number of years since bar passage & $\begin{array}{l}\text { Min.-Max: } 1-75 \\
\text { SD }=13, \text { Mean= } 21\end{array}$ \\
\hline $\begin{array}{l}\text { Rural or Urban } \\
\text { Practice }\end{array}$ & $\begin{array}{l}0=\text { urban area } \\
1=\text { rural area }\end{array}$ & $\begin{array}{l}82.2 \%(1796) \\
17.8 \%(390) \\
\end{array}$ \\
\hline Practice Types & $\begin{array}{l}\text { Solo Practitioner or Small Firm } \\
\text { Medium/large Firm (excluded category) } \\
\text { In-house Counsel } \\
\text { Government \& Legal Aid } \\
\text { Other }\end{array}$ & $\begin{array}{l}46.1 \%(1027) \\
28.1 \%(625) \\
8.1 \%(179) \\
14.9 \%(331) \\
2.8 \%(62)\end{array}$ \\
\hline Law School Prestige & $\begin{array}{l}\text { Ranked in Top } 10 \\
\text { Ranked } 11 \text { to } 20 \\
\text { Ranked } 21 \text { to } 50 \\
\text { Ranked } 51 \text { to } 100 \\
\text { Ranked to } 150 \\
\text { Ranked above } 151 \text { (excluded category) }\end{array}$ & $\begin{array}{l}6.4 \%(136) \\
3.0 \%(64) \\
48.8 \%(49) \\
10.6 \%(225) \\
6.2 \%(132) \\
25.0 \%(532)\end{array}$ \\
\hline
\end{tabular}


Table 2: Attorneys' Perceptions of Unfair Treatment

\begin{tabular}{|c|c|c|c|}
\hline & $\begin{array}{c}\text { Unfair } \\
\text { Treatment: Race }\end{array}$ & $\begin{array}{c}\text { Unfair Treatment: } \\
\text { Gender }\end{array}$ & $\begin{array}{c}\text { Unfair Treatment: } \\
\text { Age }\end{array}$ \\
\hline VARIABLE & $\begin{array}{c}\text { Ordered Logit } \\
\text { Coefficients (RSE) }\end{array}$ & $\begin{array}{c}\text { Ordered Logit } \\
\text { Coefficients (RSE) }\end{array}$ & $\begin{array}{c}\text { Ordered Logit } \\
\text { Coefficients (RSE) }\end{array}$ \\
\hline \multicolumn{4}{|c|}{ Individual Characteristics } \\
\hline White Females & $-.013(.298)$ & $4.40 *(.184)$ & $.893 * *(.107)$ \\
\hline Nonwhite Males & $3.09 * *(.312)$ & $-.989(1.04)$ & $.412(.279)$ \\
\hline Nonwhite Females & $3.56 * *(.300)$ & $4.42 * *(.274)$ & $.698 * *(.232)$ \\
\hline Years of Practice & $.007(.010)$ & $-.012(.006)$ & $-.090 * *(.006)$ \\
\hline Career Satisfaction & $-.123 *(.054)$ & $-.129 * *(.039)$ & $-.154 * *(.028)$ \\
\hline \multicolumn{4}{|c|}{ Practice Characteristics } \\
\hline Rural Area & $-.526(.326)$ & $-.305(.188)$ & $-.115(.137)$ \\
\hline Solo/Small Firm Practice & $.148(.266)$ & $.321(.168)$ & $-.066(.122)$ \\
\hline In-house Counsel & $-.275(.420)$ & $.227(.227)$ & $-.246(.157)$ \\
\hline Government/Legal Aid & $.847 * *(.309)$ & $.142(.202)$ & $-.172(.157)$ \\
\hline Other Practice Type & $.531(641)$ & $.104(.424)$ & $-.511(.350)$ \\
\hline \multicolumn{4}{|l|}{ Law School Prestige } \\
\hline Top 10 & $-.463(.490)$ & $.001(.285)$ & $-.091(.240)$ \\
\hline Ranked 11-20 & $-.306(.472)$ & $-.154(.442)$ & $.320(.328)$ \\
\hline Ranked 21-50 & $-.379(.264)$ & $.206(.175)$ & $.423 * *(.126)$ \\
\hline Ranked 51-100 & $-.564(.395)$ & $.146(.245)$ & $.055(.176)$ \\
\hline Ranked 101-150 & $-1.74 * *(.567)$ & $.378(.258)$ & $.033(.229)$ \\
\hline Cut 1 & $2.09(.531)$ & $2.40(.387)$ & $-1.71(.263)$ \\
\hline Cut 2 & $3.48(.533)$ & $4.02(.393)$ & $-.314(.262)$ \\
\hline Cut 3 & $5.78(.638)$ & $6.18(.421)$ & $1.69(.283)$ \\
\hline Wald Chi-Squared & 313.48 & 651.92 & 366.88 \\
\hline Prob $>\operatorname{chi}(2)$ & 0.000 & 0.000 & 0.000 \\
\hline Pseudo R2 & 0.243 & 0.373 & 0.151 \\
\hline$N$ & 1966 & 1981 & 1981 \\
\hline
\end{tabular}

Notes: $* \mathrm{p}<.05$ (two-tailed). ${ }^{*} \mathrm{p}<.01$ (two-tailed) .Excluded categories are "White males," "Medium/large firm," and "Law Schools ranked below 151." 


\section{Figure 1}

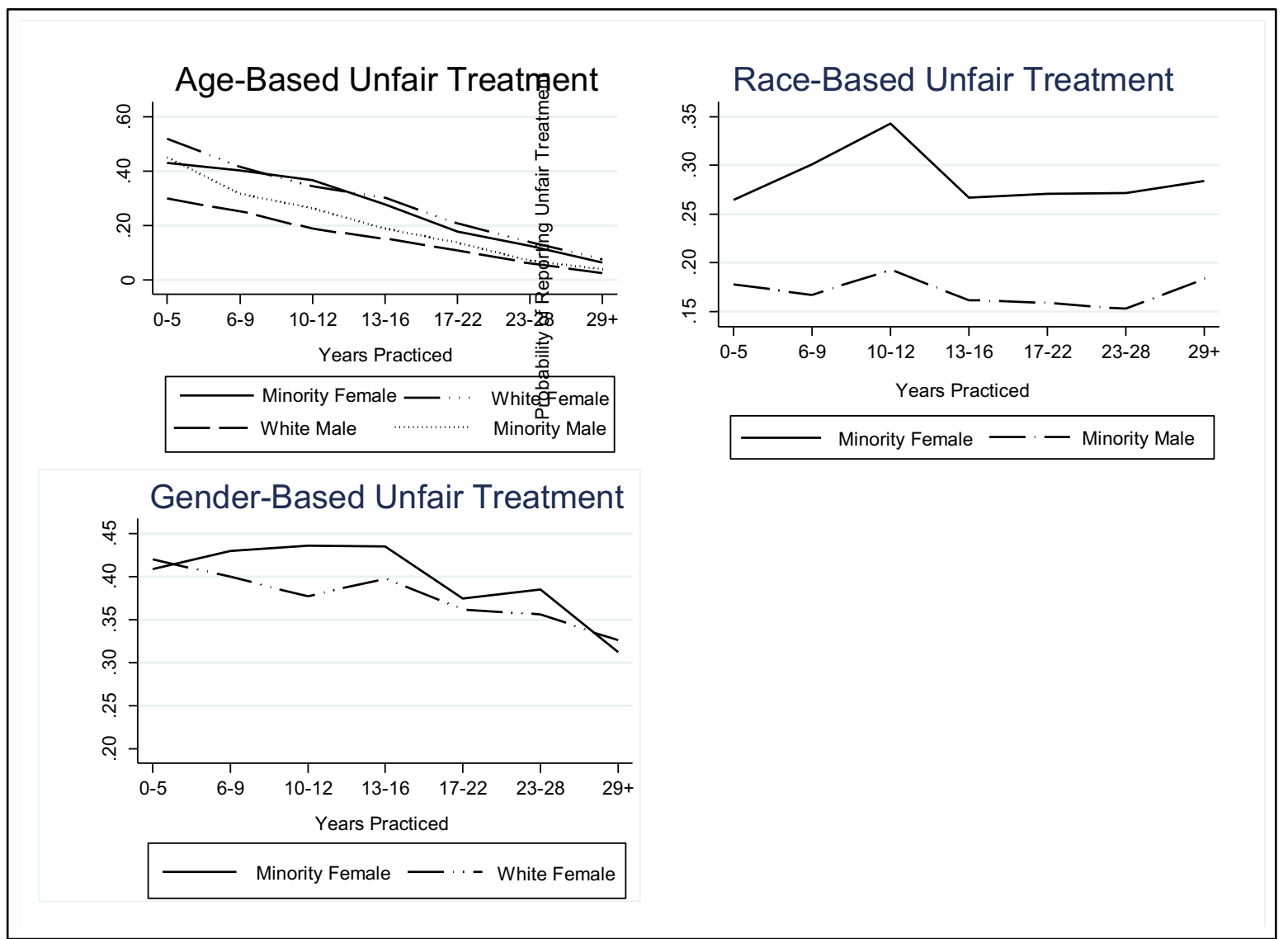

Notes: Y-axis shows probability of reporting that unfair treatment was experienced occasionally or often. Each "tick" on the $\mathrm{x}$-axis represents about $15 \%$ of the entire sample. 
Table 3: Career Satisfaction of Attorneys

\begin{tabular}{|c|c|c|}
\hline & Model 1 & Model 2 \\
\hline VARIABLE & $\begin{array}{c}\text { Ordered Logit } \\
\text { Coefficients (RSE) }\end{array}$ & $\begin{array}{c}\text { Ordered Logit } \\
\text { Coefficients (RSE) }\end{array}$ \\
\hline \multicolumn{3}{|c|}{ Individual Characteristics } \\
\hline White Females & $-.025(.094)$ & $.166(.128)$ \\
\hline Nonwhite Males & $.070(.192)$ & $.153(.207)$ \\
\hline Nonwhite Females & $-.501 * *(.192)$ & $-.223(.245)$ \\
\hline Years of Practice & $.035^{* *}(.000)$ & $.028 * *(.004)$ \\
\hline \multicolumn{3}{|c|}{ Practice Characteristics } \\
\hline Rural Area & $-.107(.111)$ & $-.097(.113)$ \\
\hline Solo/Small Firm & $-.270 * *(.098)$ & $-.296 * *(.099)$ \\
\hline In-house Counsel & $.050(.158)$ & $.023(.157)$ \\
\hline Government/Legal Aid & $-.062(.128)$ & $-.078(.131)$ \\
\hline Other Practice Type & $-1.26^{* *}(.216)$ & $-1.29 * *(.226)$ \\
\hline \multicolumn{3}{|l|}{ Law School Prestige } \\
\hline Top 10 & $-.174(.169)$ & $-.166(.176)$ \\
\hline Ranked 11-20 & $-.153(.228)$ & $-.156(.231)$ \\
\hline Ranked 21-50 & $-.132(.108)$ & $.068(.109)$ \\
\hline Ranked 51-100 & $-.092(.166)$ & $.072(.101)$ \\
\hline Ranked 101-150 & $-.173(.190)$ & $-.166(.128)$ \\
\hline \multicolumn{3}{|c|}{ Perceptions of Unfairness } \\
\hline Racial Unfairness & --- & $-.091(.126)$ \\
\hline Gender Unfairness & --- & $-.096(.082)$ \\
\hline Age Unfairness & --- & $-.270 * *(.061)$ \\
\hline Cut 1 & $-4.48(.291)$ & $-5.28(.332)$ \\
\hline Cut 2 & $-2.79(.202)$ & $-3.56(.253)$ \\
\hline Cut 3 & $-1.63(.187)$ & $-2.37(.243)$ \\
\hline Cut 4 & $-1.42(.184)$ & $-2.15(.242)$ \\
\hline Cut 5 & $-.957(.181)$ & $-1.69(.241)$ \\
\hline Cut 6 & $-.017(.179)$ & $-.729(.238)$ \\
\hline Cut 7 & $1.61(.182)$ & $.895(.239)$ \\
\hline$N$ & 2005 & 1964 \\
\hline Wald Chi-Squared & 166.88 & 198.58 \\
\hline Prob $>\operatorname{chi}(2)$ & 0.000 & 0.000 \\
\hline Pseudo R2 & 0.023 & 0.028 \\
\hline
\end{tabular}

Notes: $* \mathrm{p}<.05$ (two-tailed). ** $\mathrm{p}<.01$ (two-tailed).Excluded categories are "White males," "Medium/large firm," and "Law Schools ranked below 151". 
${ }^{1}$ Studies of juror reactions to female attorneys point to gendered perceptions of lawyers that influence assessments of capability, expertise, and intelligence (Sumoski 2001; Hahn and Clayton 1996, but see Cohen and Peterson 1981; Sigal et al. 1985). However, the research provides mixed evidence on the question of whether female advocates are less successful in the courtroom (Szmer et al. 2013; Szmer et al. 2010; Kaheny et al. 2011).

${ }^{2}$ Women lawyers earn less and work in less prestigious positions (Dinovitzer, Reichman, and Sterling 2009; Fuchs Epstein et al. 1995; Kay and Hagan 2003), are hired less frequently (Gorman 2005), and appear to experience a persistent glass ceiling (Carson 2004; Chui and Leicht 1999). With respect to race, minority lawyers earn less and work in less prestigious positions than their white counterparts (Carson 2004; Chambliss 2000). Attrition remains a major problem for minority lawyers (Sander 2006).

${ }^{3}$ The sample for the study was $91 \%$ white and $66 \%$ male. National assessments estimate that $88 \%$ of US attorneys are white, and 65\% are male (American Bar Association 2015). State estimates indicate that $87 \%$ of North Carolina attorneys are white, and 58\% are males (North Carolina Bar 2013). The sample also mirrors national estimates on type of work, as $75 \%$ of US attorneys are in private practice, $8 \%$ are government attorneys, $8 \%$ are in private industry, and 1\% serve in legal aid positions (American Bar Association 2015). In our sample, $73 \%$ of respondents were in private practice, $12 \%$ were government attorneys, $6 \%$ in private industry, and $2 \%$ were in legal aid.

${ }^{4}$ We also tried models (not shown) that used a squared term of years since passing the bar to assess curvilinear effects. The results were largely the same as the models shown with respect to our main independent variables, and predicted probabilities showed no differences from the models presented.

${ }^{5}$ Several of our controls also serve as proxies for attorney quality: law school prestige, practice type, and career satisfaction.

${ }^{6}$ When the excluded category is rotated to facilitate comparisons, we see that minority women are not significantly different from either white women or minority men in terms of perceptions of age bias.

${ }^{7}$ See the online appendix for results of career satisfaction models with minority women as the excluded category.

${ }^{8}$ We emphasize that because our data are not longitudinal, we cannot test whether perceptions of unfairness actually cause lower career satisfaction, or vice versa.

${ }^{9}$ The only moderately correlated variables in this model are the "white female" and "gender unfairness" variables $(\mathrm{r}=.6)$. However, we note that no variance inflation factor was higher than 2.5 , which is below the 3.0 standard typically followed as an appropriate guideline (Fox and Monette 1992). 